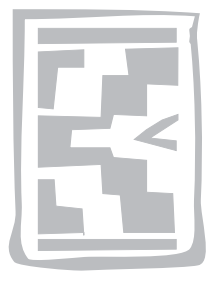

\title{
Aspects of the ecology of the Asian tapeworm, Bothriocephalus acheilognathi Yamaguti, 1934 in yellowfish in the Vaal Dam, South Africa
}

\author{
A. BERTASSO and A. AVENANT-OLDEWAGE \\ Department of Zoology, University of Johannesburg*, P.O. Box 524, Auckland Park, 2006 South Africa
}

\begin{abstract}
BERTASSO, A. \& AVENANT-OLDEWAGE, A. 2005. Aspects of the ecology of the Asian tapeworm, Bothriocephalus acheilognathi Yamaguti, 1934 in yellowfish in the Vaal Dam in South Africa. Onderstepoort Journal of Veterinary Research, 72:207-217

Seasonal surveys were conducted at the Vaal Dam between April 2000 and January 2001. Twenty smallmouth yellowfish (Labeobarbus aeneus) and 20 largemouth yellowfish (Labeobarbus kimberleyensis) were collected with the aid of gill nets. Surface water quality variables were included. The cestodes were identified as either Bothriocephalus acheilognathi Yamaguti, 1934 or "other cestode spp.". The majority (99.8\%) of the cestodes found in both yellowfish species were identified as $B$. acheilognathi (Asian tapeworm). The prevalence, mean intensity and abundance of $B$. acheilognathi in both yellowfish species were calculated. Ecological parameters including species specificity, seasonality, gender specificity and relationships between fish size and the Asian tapeworm prevalence were also included. In this study, B. acheilognathi preferred L. kimberleyensis over $L$. aeneus although a low intensity was observed in smallmouth yellowfish. Furthermore, the infection (in terms of prevalence, abundance and mean intensity) in largemouth yellowfish was markedly higher. Seasonal patterns observed in the Asian tapeworm's infection of smallmouth yellowfish are attributed to breeding and subsequent feeding patterns of this fish species with relatively high infections recorded in winter and spring. For L. kimberleyensis no explanation can be given regarding the seasonal patterns observed for the mean intensity and abundance of $B$. acheilognathi. The maximum and minimum mean intensity and abundance values in largemouth yellowfish were recorded in autumn and spring, respectively. In addition, the prevalence of $B$. acheilognathi was consistently high in all four seasons.
\end{abstract}

Keywords: Asian tapeworm, Bothriocephalus acheilognathi, Labeobarbus aeneus, Labeobarbus kimberleyensis, seasonal prevalence, yellowfish

\section{INTRODUCTION}

Surveys conducted by the fish parasitology group have shown unexpectedly high numbers of helminth parasites in yellowfish species in the Vaal Dam. The high number of helminth parasites can be attributed to Bothriocephalus acheilognathi which has been introduced with cyprinid fish into South Africa from Asia (Brandt, Van As, Schoonbee \& Hamilton-Attwell

\footnotetext{
* Formerly Rand Afrikaans University Accepted for publication 15 April 2005-Editor
}

1981). The Asian tapeworm, originally a parasite of the Chinese grass carp (Ctenopharyngodon idella Valenciennes, 1844) and the silver carp (Hypothalmichthys molitrix Valenciennes, 1844) in the southern parts of China (Boomker, Huchzermeyer \& Naudé 1980), has spread rapidly to other countries by means of infected fish (Pool 1987) and has adapted itself successfully to the common carp (Cyprinus carpio Linnaeus, 1758) (Boomker et al. 1980).

In South Africa, bothriocephalid parasites have been found in various dams and freshwater systems in 
Gauteng Province. Localities in South Africa where $B$. acheilognathi has been found include the Komatipoort area (Mpumalanga Province) (Boomker et al. 1980), Marble Hall (Mpumalanga Province) (Brandt et al. 1981), Boskop Dam (KwaZulu-Natal Province) (Van As, Schoonbee \& Brandt 1981), Hartbeespoort Dam (North West Province), Piet Gouws Dam (Limpopo Province) (Mashego 1982), Olifants River (Limpopo Province) (Mashego 1982), Glen Alpine Dam (Limpopo Province) (Mashego 1982) and the Vaal Dam (Gauteng Province) (Mashego 1982). The tapeworm's presence in most of the localities mentioned above can be attributed to the supply of common carp fry to commercial farmers (Boomker et al. 1980). However, according to Mashego (1982) its presence in the Vaal Dam cannot be accounted for. Brandt et al. (1981) mentioned the possibility that this tapeworm was imported into South Africa with the common carp as long ago as 1859 or with the Dinkelsbühl Aischgrund variety of the common carp in 1952. Cyprinus carpio has been found in the Vaal Dam but its introduction date is uncertain.

Bothriocephalus acheilognathi was originally described as three different species from wild fish in Japan (as B. acheilognathi Yamaguti, 1934 and Bothriocephalus opsariichthydis Yamaguti, 1934) and from grass carp (C. idella) from South China (as Bothriocephalus gowkongensis Yeh, 1955) (Paperna 1996). These three species were later recognised as being identical (Körting 1975; Molnár 1977) with the name $B$. acheilognathi taking priority. Pool (1988) believes that the three species, $B$. acheilognathi, Bothriocephalus kivuensis and Bothriocephalus aegyptiacus, are identical, with $B$. acheilognathi having priority. Various authorities (as cited by Pool \& Chubb 1985 and Pool 1988) noted that Bothriocephalus opsariichthydis Yamaguti, 1934, Bothriocephalus fluviatilis Yamaguti, 1952, B. gowkongensis Yeh, 1955, Bothriocephalus phoxini Molnár, 1968 and Schyzocotyle fluviatilis Akhmerov, 1960 are the same species as $B$. acheilognathi Yamaguti, 1934. Pool \& Chubb (1985) concluded that there is only one Bothriocephalus species parasitizing cyprinid fish and suggested the continued use of the name $B$. acheilognathi. Cestodes in this study were identified as either $B$. acheilognathi or "other cestode spp.".

The purpose of this article is to provide a brief description of the parasite's infection, seasonality, gender specificity and species (host) specificity in the two yellowfish species sampled. A comparison between the parasite's infection in Labeobarbus aeneus and its infection in Labeobarbus kimberleyensis is also included.

\section{MATERIALS AND METHODS}

\section{Study location}

Four surveys were conducted in the Vaal Dam at Groot Eiland, also known as RAU Island-one per season, namely in April 2000 (early autumn), June 2000 (winter), October 2000 (late spring) and January 2001 (summer). The Vaal Dam is located in the upper reaches of the Vaal River.

\section{Water quality}

Water quality data for the duration of the project were obtained from the Rand Water Board, and were collected during routine monitoring activities made by the Rand Water Board. Standard techniques were used by the Rand Water Board to analyse the water samples. For some months various parameters were not measured, the reasons being that sampling and/ or measuring instruments were either not in working order or being serviced. The following surface water variables were included: $\mathrm{pH}$, temperature, electrical conductivity, dissolved oxygen and light penetration.

\section{Collection of fish and cestodes}

A field laboratory was set up for each survey. The fish species collected during the four surveys were L. aeneus (smallmouth yellowfish) and L. kimberleyensis (largemouth yellowfish). The fish were identified based on the size of the snout as suggested by Skelton (2001). Twenty largemouth and 20 smallmouth yellowfish per survey were collected using gill nets consisting of four sections with varying stretched mesh sizes of 90, 110 and $130 \mathrm{~mm}$, respectively. They were weighed (in grams) and measured (fork length in millimetres). The fish were killed by severing the spinal cord behind the head and were subsequently dissected by making an insertion from the anus towards the head. Once they had been dissected, the intestines were removed and placed in a normal saline solution in petri dishes for examination. Methods described by Khalil (1991) were used for processing the platyhelminth parasites found during the surveys. Parasites were collected as soon as possible after the death of the fish to prevent any deterioration. The intestines were pulled open carefully using two sharp tweezers to ensure that the cestodes were kept intact. Each cestode was carefully and slowly dislodged from the intes- 
tinal wall, ensuring that it remained intact. They were transferred to a clean sampling bottle containing normal saline solution, which was then shaken vigorously for a few minutes to dislodge debris and induce muscle fatigue in the helminths, which in turn, deters strong contraction of the scolices and relaxes them. While swirling the sampling bottle, an equal amount (equal to the amount of saline solution already present in the sampling bottle) of a hot alcohol-formaldehyde-acetic acid (AFA) solution was added to kill and fix the specimens. Specimens were then stored in $70 \%$ alcohol.

\section{Identification of cestodes}

The cestodes were stained with Grenacher's borax armine stain (Pantin 1964) and identified.

\section{Statistical analyses}

All specimens were counted and the totals obtained were used for statistical analyses which were conducted by the University Statistical Consultation Services. Prevalence, abundance and mean intensity of $B$. acheilognathi were calculated per season for each fish species. Infection statistics were calculated by making use of the definitions set by Margolis, Esch, Holmes, Kurtis \& Schad (1982) and Bush, Lafferty, Lotz \& Shostak (1997).

Data was analysed to determine the seasonality (using ANOVA and then Scheffe or Dunnet T3) and species and gender specificity (using Pearson Chisquare test and T-tests) of $B$. acheilognathi. A comparison between the infections in the two fish species was done (using the T-test). In addition, the infection of $B$. acheilognathi (intensity) in each fish species was compared to the size (fork length) of the fish sampled. Regression analysis was used to determine if any correlations existed.

Digital micrographs of stained specimens were taken using a Zeiss Axioplan 2 Imaging microscope.

\section{RESULTS}

\section{Water quality}

Surface water variables and data obtained in this study are presented in Table 1.

\section{Identification of cestodes}

According to Mashego (1982), the classification of the bothriocephalid worms is based primarily on the shape of the scolex. Pool (1984) concluded from his study on $B$. acheilognathi that the identification of adults should be based on the heart-shaped scolex and prominent square apical disc. The identification of the bothriocephalid cestodes in this study was therefore based on these characteristics.

Specimens found in the current study were compared to sketches provided by various authorities (Yamaguti 1934; Yeh 1955; Molnár \& Murai 1973; Mashego 1982) as well as the diagnosis of $B$. acheilognathi (as B. gowkongensis) by Yeh (1955), as cited by Paperna (1996). Micrographs and sketches of $B$. acheilognathi collected during the four surveys are presented in Fig. 1. When reviewing available sketches it is the authors' opinion that the scolex of specimens from the current study compared fairly well with many of the Bothriocephalus species that have a heart-shaped scolex (Fig. 1A). As mentioned in Paperna (1996), the eggs are operculated (Fig. 1F) and the vitellaria laterally scattered (Fig. 1D).

According to the diagnosis given in Paperna (1996), mature and gravid segments vary in breadth and length. However, in this study this was not the case. Most segments were broader than they were long (Fig. 1B and C). We however, disagree with the system of labelling the reproductive system as proposed by Yamaguti (1934), and consider that, after reviewing the available literature, it should be as indicated in Fig. 1E.

TABLE 1 Summary of water quality variables recorded seasonally at the Vaal Dam

\begin{tabular}{|l|l|l|l|l|l|}
\hline \multirow{2}{*}{ Survey } & $\mathrm{pH}$ & Temperature & $\begin{array}{l}\text { Electrical } \\
\text { conductivity }\end{array}$ & $\begin{array}{l}\text { Dissolved } \\
\text { oxygen }\end{array}$ & $\begin{array}{l}\text { Secchi disc } \\
\text { readings }\end{array}$ \\
\cline { 2 - 6 } & $(\mathrm{pH}$ units) & $\left({ }^{\circ} \mathrm{C}\right)$ & $(\mathrm{mS} / \mathrm{m})$ & $\left(\mathrm{mg} / \ell \mathrm{O}_{2}\right)$ & $(\mathrm{cm})$ \\
\hline Autumn (April 2000) & 7.60 & - & 17.00 & - & - \\
Winter (June2000) & 7.34 & 19.90 & 16.00 & 12.50 & 30.00 \\
Spring (October 2000) & 8.00 & 21.40 & 17.00 & - & 28.00 \\
Summer (January 2001) & 8.26 & 25.00 & 23.00 & 6.30 & 28.00 \\
\hline
\end{tabular}

- No data available 

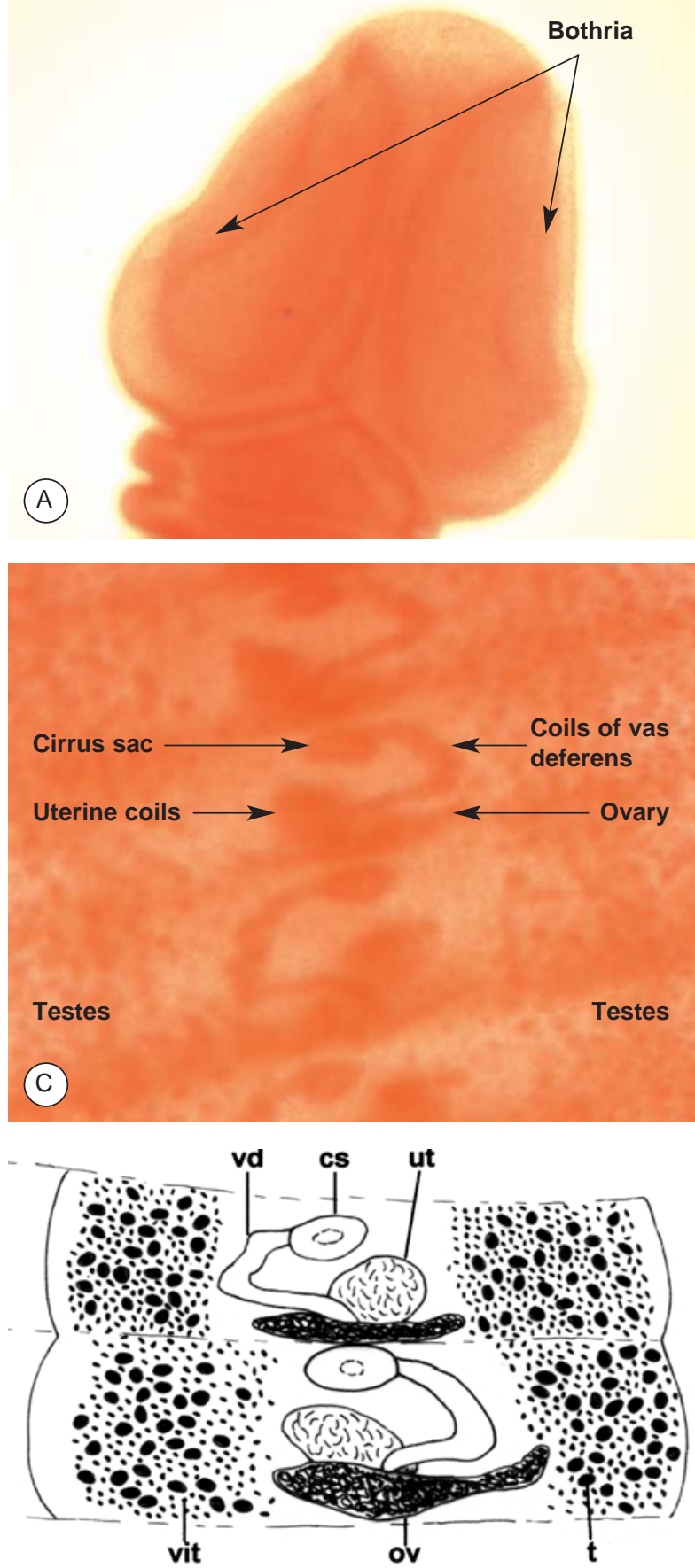

(E) Abbreviations: cs - cirrus sac; ut - uterus; ov - ovary; vit - vitellaria; $t$ - testes; $v d$ - vas deferens
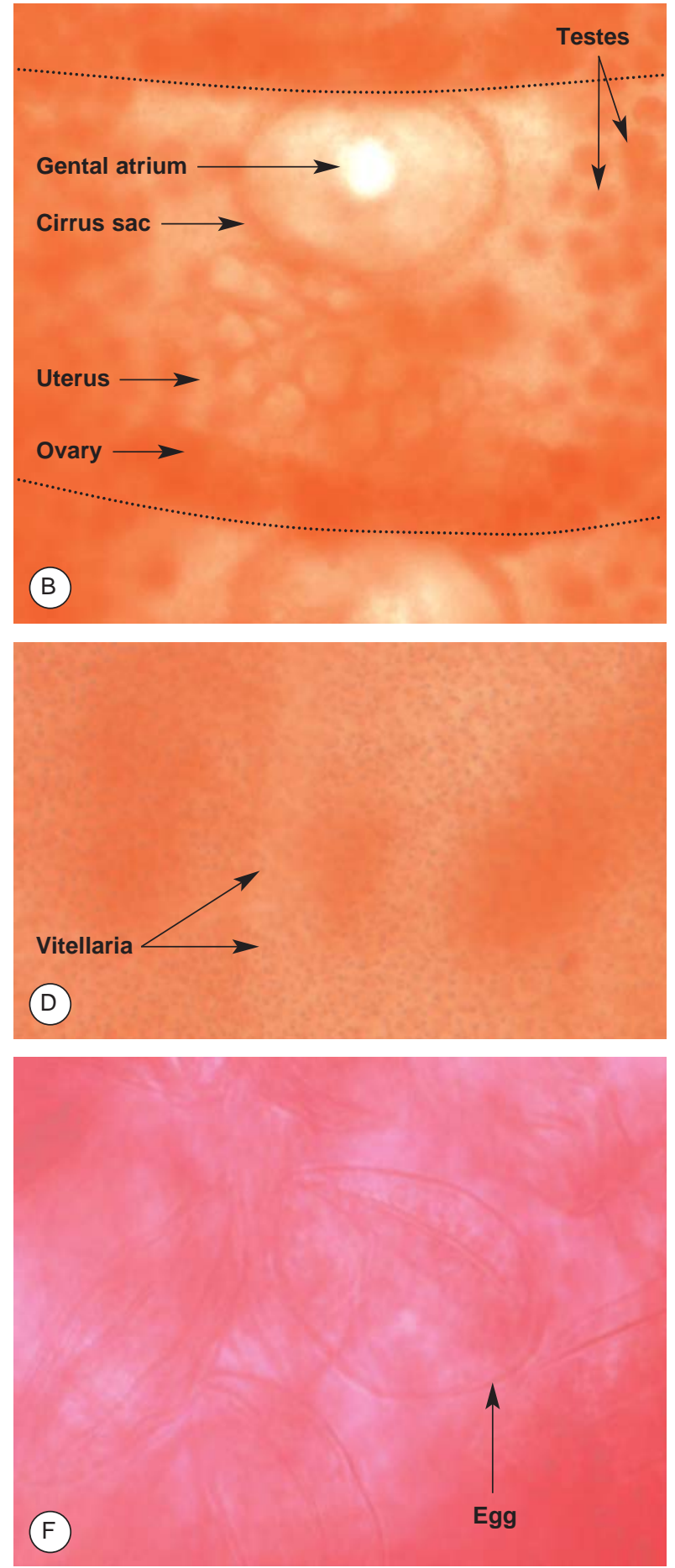

FIG. 1 Micrographs and sketches of Bothriocephalus acheilognathi collected during the four seasons of the survey in the Vaal Dam
A Heart-shaped scolex with bothria
B Mature proglottid with reproductive organs
C Young adult proglottid
D Vitellaria scattered
E Sketch of a young adult proglottid
F Operculated egg 
TABLE 2 Number of cestodes collected from Labeobarbus aeneus and Labeobarbus kimberleyensis at the Vaal Dam during the four seasons

\begin{tabular}{|l|l|l|l|l|}
\hline \multirow{2}{*}{ Survey } & \multicolumn{2}{|l|}{ Labeobarbus aeneus $(n=80)$} & \multicolumn{2}{l|}{ Labeobarbus kimberleyensis $(n=80)$} \\
\cline { 2 - 5 } & B. acheilognathi & Other cestode spp. & B. acheilognathi & Other cestode spp. \\
\hline Autumn (April 2000) & 4 & 0 & 3417 & 4 \\
Winter (June2000) & 298 & 0 & 1651 & 0 \\
Spring (October 2000) & 256 & 0 & 2040 & 1 \\
Summer (January 2001) & 24 & 0 & 8216 & 8 \\
\hline Total & 582 & 0 & 8228 & \\
\hline Total cestodes & 582 & & & 8 \\
\hline
\end{tabular}

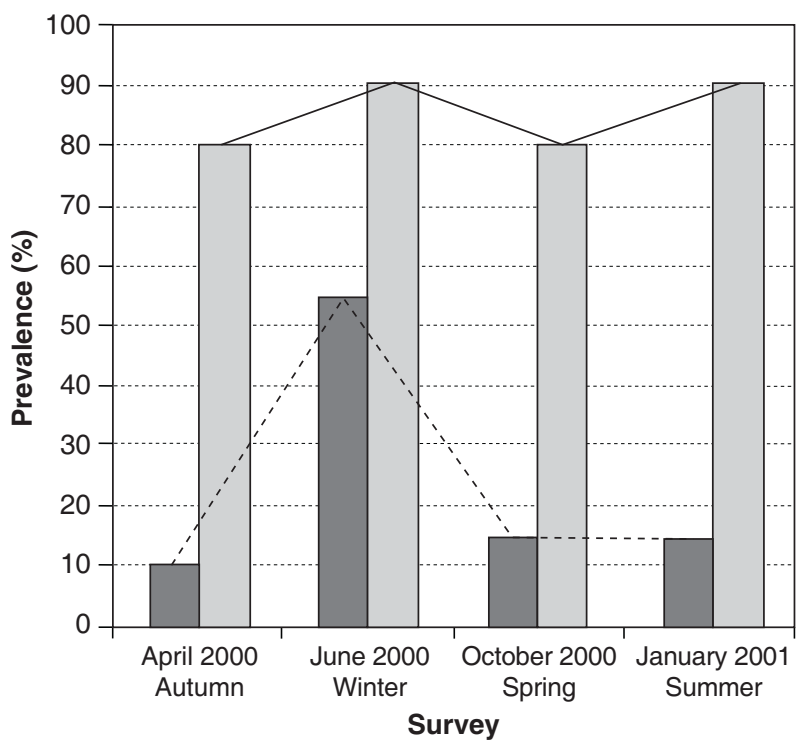

$\square$ Labeobarbus aeneus $(n=80)$

$\square$ Labeobarbus kimberleyensis $(n=80)$

- - Labeobarbus aeneus trendine

- Labeobarbus kimberleyensis trendine

FIG. 2 Graph depicting the prevalence of Bothriocephalus acheilognathi in Labeobarbus aeneus and Labeobarbus kimberleyensis during the four seasons

\section{Parasite numbers}

The tapeworms encountered in this study were grouped as either $B$. acheilognathi or "other cestode spp.". The number of $B$. acheilognathi and other cestode spp. collected during the four seasons of the survey is tabulated in Table 2. Of the 160 fish sampled, only 19 out of 80 L. aeneus harboured $B$. acheilognathi while none harboured other cestode spp.; and 68 out of 80 L. kimberleyensis harboured $B$. acheilognathi while only six harboured other cestode spp.

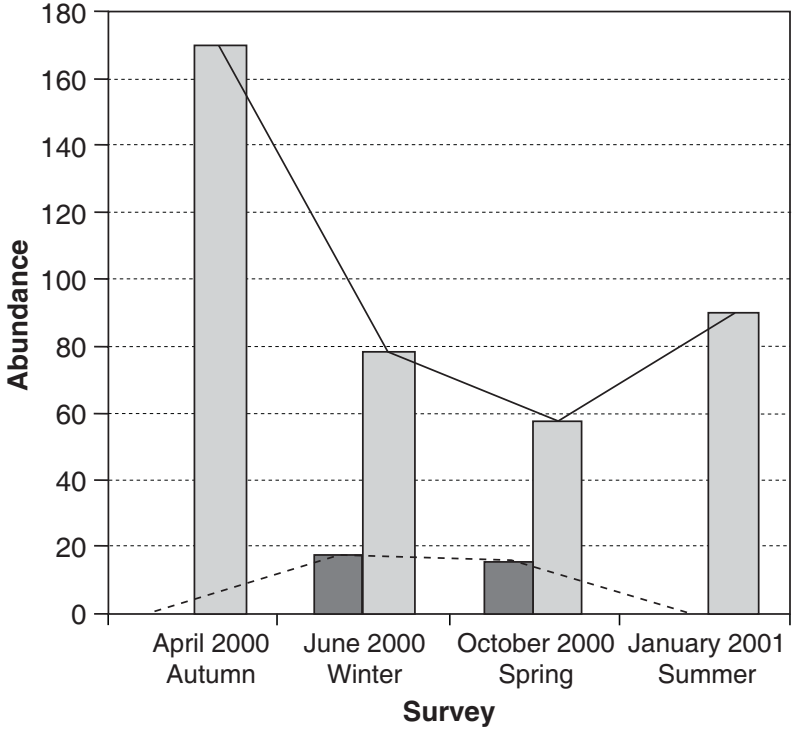

$\square$ Labeobarbus aeneus $(n=80)$

$\square$ Labeobarbus kimberleyensis $(n=80)$

- - Labeobarbus aeneus trendine

- Labeobarbus kimberleyensis trendine

FIG. 3 Graph depicting the abundance (relative density) of Bothriocephalus acheilognathi in Labeobarbus aeneus and Labeobarbus kimberleyensis during the four seasons of the survey

\section{Infection statistics of $B$. acheilognathi}

The percentage of hosts (prevalence) infected with $B$. acheilognathi, and its intensity (mean intensity) and abundance (relative density) in both $L$. aeneus and $L$. kimberleyensis are illustrated graphically in Fig. 2, 3 and 4, respectively. A statistical comparison (T-test) of the two fish species in terms of $B$. acheilognathi prevalence, abundance and mean intensity is also included to determine whether or not there are significant differences between fish species. 


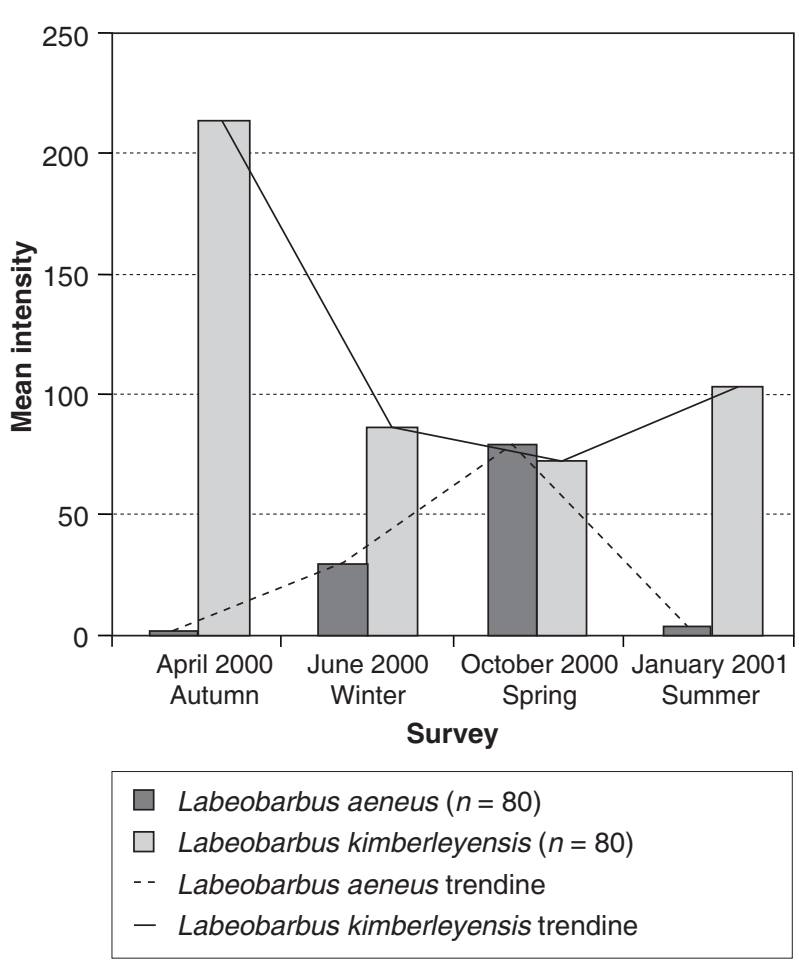

FIG. 4 Graph depicting the mean intensity of Bothriocephalus acheilognathi in Labeobarbus aeneus and Labeobarbus kimberleyensis during the four seasons

\section{Prevalence}

The prevalence of $B$. acheilognathi in L. kimberleyensis was relatively constant over all seasons, ranging from $80-90 \%$, whereas the prevalence in $L$. aeneus was fairly constant (10-15\%) in autumn, spring and summer followed by a considerable increase in winter (55 \%) (Fig. 2). When comparing its prevalence in the two fish species, that in $L$. kimberleyensis was considerably higher. Statistical analyses indicate that, there was a significant difference (T-test, $P=0.001$ ) in its prevalence in the two fish species.

\section{Abundance (relative density)}

During all surveys, the abundance of the Asian tapeworm was considerably higher in L. kimberleyensis (Fig. 3). In this fish species, abundance values ranged from 55.0 (spring) to 170.9 (autumn) while in $L$. aeneus these values ranged from 0.2 (autumn) to 14.9 (winter). The following seasonal trend was observed for largemouth yellowfish: values decreased from autumn to winter and then again in spring. The latter was followed by an increase in summer. For smallmouth yellowfish the opposite trend was observed. Values increased from autumn to winter and were followed by a decrease in spring and a further decrease in summer. Statistical analyses indicate that there was a significant difference (T-test, $P=0.011$ ) between the relative densities of $B$. acheilognathi in the two fish species sampled.

\section{Mean intensity}

Excluding spring, the infection was considerably more intense in L. kimberleyensis (Fig. 4). The highest value recorded for $L$. kimberleyensis was 213.6 in autumn and the lowest value was 68.8 recorded in spring. During the remaining seasons the mean intensity decreased to 102.2 and 85.8 in summer and winter respectively. Similarly, the mean intensities in $L$. aeneus differed considerably from 2.00 in autumn to 78.7 in spring. During winter and summer a mean intensity of 27.1 and 4.3 , respectively, was recorded. Statistical analyses indicate that, there could be a significant difference between the mean intensities of $B$. acheilognathi in the two fish species (T-test, $P$ value was slightly above 0.05 at 0.053 ) but due to either the sample size being too small or the variance being too big this cannot be said for certain.

\section{Ecological parameters}

\section{Gender specificity}

In both fish species, there were no significant differences (T-test, $P$ values $>0.05$ ) in the average number of $B$. acheilognathi found in males and females even though the average number in males and females differed. In $L$. aeneus the average numbers of $B$. acheilognathi in male and in female fish were 12.85 and 2.70 , respectively. In L. kimberleyensis the average numbers were 91.43 and 107.42 , respectively.

In addition, the presence or absence of $B$. acheilognathi is not dependent on the gender of fish species (Pearson Chi-square test; $P$ values for both fish species $>0.05)$. Similar numbers of male (7) and female (12) $L$. aeneus and male (37) and female (31) L. kimberleyensis were found to harbour $B$. acheilognathi. In $L$. aeneus, the prevalence of $B$. acheilognathi in males and females was 0.21 and 0.26 , respectively. Similarly, in $L$. kimberleyensis the prevalence of $B$. acheilognathi was 0.84 in males and 0.86 in females.

\section{Seasonality}

In $L$. aeneus, the highest number of $B$. acheilognathi were observed during the winter survey while in L. kimberleyensis the highest number was observed during the spring survey (Table 2). From 


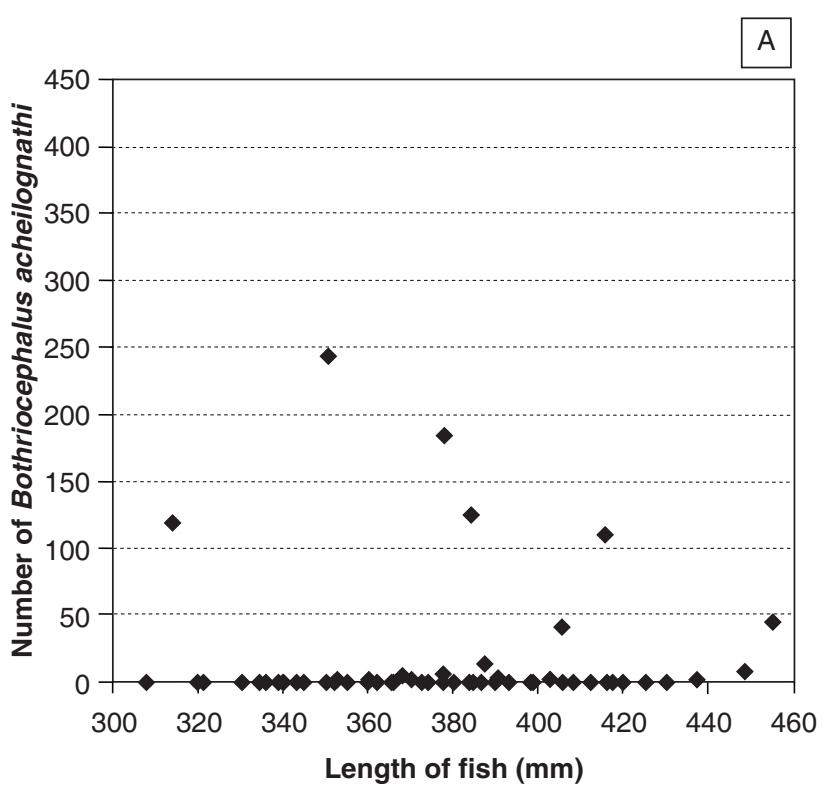

- Labeobarbus aeneus

$P$ value $=-0.089$

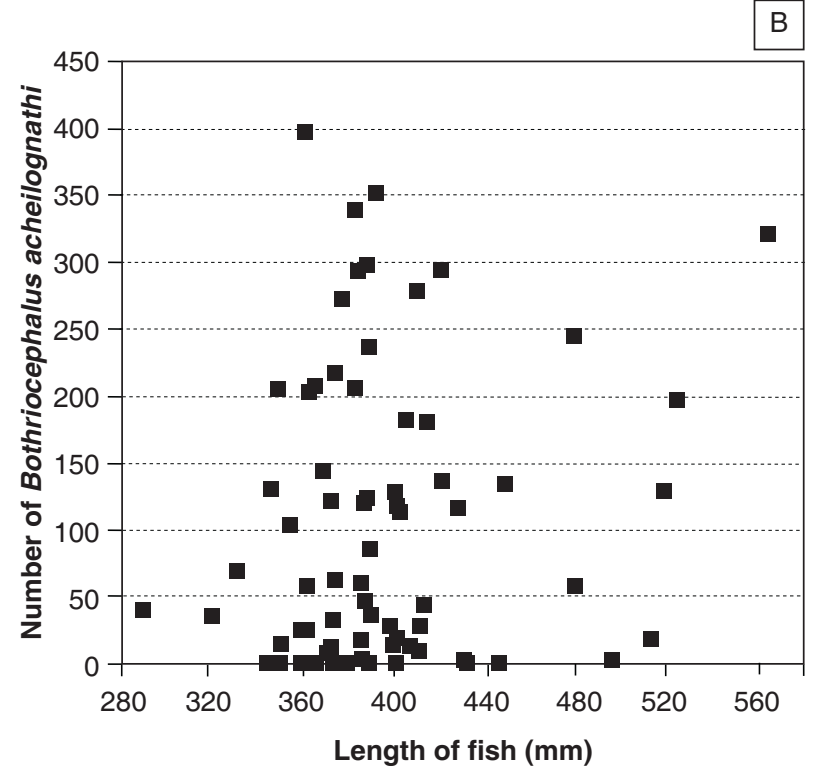

- Labeobarbus kimberleyensis $P$ value $=0.174$

FIG. 5 Graphs showing that there was no correlation between the size (fork length) of Labeobarbus aeneus (A) and Labeobarbus kimberleyensis (B) sampled during the four seasons and the number of Bothriocephalus acheilognathi. The statistically calculated $P$ value is included

the statistical analyses (Pearson Chi-square test) performed on the data, the presence/absence of $B$. acheilognathi in $L$. aeneus was dependent on the season $(P=0.002)$ with the highest number of infected fish (11) being in those caught in winter and the lowest (2) being in autumn. This was not the case for $L$. kimberleyensis. Similar numbers of L. kimberleyensis (between 16 and 18) were infected with $B$. acheilognathi during all four seasons of the survey.

However, when conducting the ANOVA test to determine if there were significant differences between seasons, the results show that there were significant $(P=0.003)$ seasonal differences based on the number of $B$. acheilognathi found in L. kimberleyensis. Post hoc tests were then undertaken to distinguish which of the seasons differed significantly. The results of the statistical analyses (Dunnet T3 test) showed that autumn and spring differed significantly with a $P$ value of 0.011 . No significant seasonal differences were determined in the number of $B$. acheilognathi found in $L$. aeneus.

\section{Species specificity}

When comparing fish species, L. kimberleyensis harboured a higher number of $B$. acheilognathi than $L$. aeneus (Table 2). The number of $B$. acheilog- nathi found in L. kimberleyensis totalled 8216 , while $L$. aeneus only had a total of $582 B$. acheilognathi in the same number of hosts (80). In addition, a higher number of $L$. kimberleyensis (68) were infected with $B$. acheilognathi than $L$. aeneus (19). From the statistical analyses (Pearson Chi-square) performed when data is pooled according to fish species, the presence/absence of $B$. acheilognathi was highly dependent on fish species, $P$ values being 0.000 .

\section{Size specificity}

As can be seen in Fig. 5, no correlations were observed between the sizes (fork lengths) of yellowfish (both smallmouth and largemouth) sampled and the number of Asian tapeworms recorded.

\section{DISCUSSION}

Exceptionally high numbers of $B$. acheilognathi and low numbers (an insignificant amount) of other cestode spp. were found in the yellowfish sampled. As highlighted by Khan \& Thulin (1991), parasites are a natural part of the aquatic community and their distribution and abundance are potentially either directly or indirectly affected by a number of biotic and abiotic factors. 


\section{Infection}

The infection of $B$. acheilognathi (in terms of prevalence, abundance and mean intensity) in L. kimberleyensis was greater than that observed in $L$. aeneus. Noticeably higher numbers of this tapeworm were observed in largemouth yellowfish and a noticeably higher number of this fish species was infected. Similar prevalence and mean intensity values to those obtained in this study were recorded for $L$. aeneus and $L$. kimberleyensis in a separate preliminary study conducted by Nickanor, Reynecke, Avenant-Oldewage \& Mashego (2002) in the Vaal Dam during 2001.

The infection statistics indicate that both prevalence and abundance of $B$. acheilognathi differed significantly (statistically) between the fish species with $L$. kimberleyensis exhibiting higher values. The mean intensity of $B$. acheilognathi was higher in L. kimberleyensis for most seasons, except in spring when the opposite was the case. In spring a small number of $L$. aeneus were infected with a relatively high number of tapeworms thereby increasing the mean intensity. It is possible that the mean intensities of the fish species differ significantly but this is uncertain in this study because either the sample size was too small or the variance was too big to distinguish between the fish species.

It would be expected that the high numbers (and subsequently high prevalence, abundance and mean intensity) of $B$. acheilognathi found in L. kimberleyensis in this study are linked to the life cycle of the tapeworm as the transmission of parasite to host is via an intermediate host eaten by the fish (Paperna 1996). Körting (1975) mentioned that the intermediate host of the Asian tapeworm for carp is a crustacean and that a number of crustaceans can act as intermediate hosts. When considering the food preference of largemouth yellowfish, it is found that it initially feeds on insects and crustaceans, but once it reaches a fork length of more than $300 \mathrm{~mm}$ it feeds on other fish (Skelton 2001). Although the majority of infected largemouth yellowfish collected during the survey varied in fork length between 360 and $420 \mathrm{~mm}$, it is possible that infected crustaceans are eaten occasionally, resulting in an infection in $L$. kimberleyensis. It was unexpected, however, to find an infection as heavy as that obtained in this study. When considering the infection of $B$. acheilognathi (in terms of prevalence, mean intensity and abundance) in relation to fish size (fork length), no correlations were recorded in L. kimberleyensis (Fig. 5). It is important to note that $L$. kimberleyensis was the first recorded host of $B$. acheilognathi (as $B$. gowkongensis) in South Africa in 1978 (Brandt et al. 1981). The type of crustacean or copepod acting as an intermediate host for $B$. acheilognathi for this fish species should be determined. This opportunistic tapeworm has already adapted successfully to the common carp, Cyprinus carpio (Körting 1974; Boomker et al. 1980) in South African waters. This carp species feeds on a range of plant and animal matter (Skelton 2001) and, more specifically, carp fry, which tend to be more heavily infected with the tapeworm, feed on zooplankton (Boomker et al. 1980). A better understanding of the intermediate host could explain the high infection of $B$. acheilognathi in L. kimberleyensis.

Other authorities, such as Marcogliese \& Esch (1989) and Williams \& Jones (1994), mention that metacestodes use planktonic or benthic copepods as intermediate hosts. If this is the case, then $L$. aeneus should be the preferred host as this fish species is broadly omnivorous with zooplankton, benthic invertebrates, vegetation, algae and detritus forming the major food of the species (Dörgeloh 1985; Skelton 2001). Although L. aeneus is not the preferred host (Nickanor et al. 2002; this study), it still becomes infected (although low) with $B$. acheilognathi. Poulin (1998) mentioned that parasites such as the Asian tapeworm that enter their host through ingestion, cannot prevent non-host species from eating the infected intermediate hosts. This method of transmission (ingestion) enables more host species to become infected. Another reason why both fish species are infected with this tapeworm could be that the intermediate copepod host species can vary considerably. Various genera of copepods have been found to be compatible intermediate hosts (Williams \& Jones 1994; Paperna 1996) and in this case it is possible that a larger crustacean, such as a crab, acts as a paratenic host-this would explain the enigma behind the higher infection observed in largemouth yellowfish. In a study conducted by De Leon, Garcia-Prieto, Leon-Regagnon \& Choudhury (2000) in Mexico it was found that helminth communities were generally more abundant in carnivorous fish species than in herbivores and detritivores. This matter needs to be researched further in order to gain a better understanding of infections by the Asian tapeworm.

\section{Seasonal trends}

In $L$. aeneus, the prevalence of $B$. acheilognathi was fairly constant except in winter when noticeably higher numbers of smallmouth yellowfish were infected. Prevalence values in winter were approximately four to five times higher than in the remain- 
ing seasons (Fig. 2). This could be due to a change in feeding regime, but during the four seasonal surveys it has been found that $L$. aeneus fed well (Bertasso 2004). Körting (1974) indicated that early spring, when plankton grows, is likely to be a significant season in terms of seasonal incidence and infective period. This was not the case, however, in $L$. aeneus in this study. In spring, the prevalence was fairly low. The reason could be that more infected food (copepods) were available in that particular winter than is usually the case. Temperature data recorded during the winter of this study (Table 1) were higher than in a previous separate study conducted in the Vaal Dam (Crafford 2000). In winter visibility (light penetration) in the Vaal Dam was at its maximum although in the remaining three seasons similar (slightly lower) values were exhibited (Table 1). It can be assumed that the finding of an increased prevalence in winter is exceptional and was caused by an external unknown factor. Statistical analyses indicated that, as a result of this high prevalence in winter, the presence of $B$. acheilognathi in $L$. aeneus is dependent on the season. In L. kimberleyensis, no trend was observed for prevalence of the Asian tapeworm throughout the four seasons (Fig. 2); a similar, very high number of fish being infected throughout the year.

Abundance values in $L$. aeneus exhibited a pattern similar to the prevalence values observed in the same fish species (Fig. 3). Values increased considerably from autumn to winter followed by a decline in spring and a further decline in summer. It is assumed that this seasonal trend is related to the breeding and subsequent feeding patterns of $L$. aeneus. Feeding habits of the host account for a large percentage of the variation in the total number of parasites per host species (Williams \& Jones 1994). The number of parasites in a host would depend on how much the host eats and whether the food is infected. In winter, the fish eat enough food to sustain them through the breeding season, which lasts from spring through to late summer (Skelton 2001) and explains the decrease in abundance recorded in spring and summer. As soon as the breeding season ends fish start eating again. This results in an increase in abundance from autumn to winter. In L. kimberleyensis, the seasonal trend in abundance could not be attributed to the fish's breeding patterns. Largemouth yellowfish breed in mid to late summer (Skelton 2001) which would mean that abundance values should be higher in winter and spring, but nevertheless the opposite was observed (Fig. 3). A sharp decrease in abundance values was recorded from autumn to winter after which abundance values remained relatively constant decreasing slightly in spring but increasing again in summer. This seasonal trend could be related to changes in the amount of food and subsequently infected food available. In autumn the high abundance relative to the other three seasons was due to the considerably higher number of $B$. acheilognathi found in the L. kimberleyensis in the survey.

A similar pattern to that recorded for the abundance of $B$. acheilognathi in L. kimberleyensis was recorded for the mean intensity (Fig. 4). This is due to the fact that most of the fish sampled during the four seasons were infected with $B$. acheilognathi. The mean intensity in $L$. aeneus also exhibited a similar pattern to that of the abundance in $L$. aeneus, except that the mean intensity peaked in spring rather than in winter (Fig. 4). Mean intensities in the smallmouth yellowfish increased considerably from autumn to winter followed by a significant increase (three times that of winter) in spring after which the intensity decreased in summer to an intensity similar to that recorded in autumn. In spring, the mean intensity recorded in $L$. aeneus was even higher than that recorded in L. kimberleyensis. Opposite seasonal trends were recorded for the mean intensity of the two fish species.

Statistical analysis indicates that the occurrence of $B$. acheilognathi in smallmouth yellowfish is dependent on the season with the highest number of fish infected in winter. However, no statistically meaningful differences were observed in the intensity of $B$. acheilognathi found during each season. The opposite is true for the largemouth yellowfish sampled in this study. Statistical analysis indicates that the occurrence of $B$. acheilognathi was not dependent on the season, even though there were significant statistical differences between the intensity of $B$. acheilognathi recorded in autumn and that recorded in spring.

\section{Fish gender and species specificity}

Statistical analysis indicates that the presence of $B$. acheilognathi is highly dependent on the species of fish with L. kimberleyensis, as mentioned above, having the highest infection of the two yellowfish species. Poulin (1998) noted that high host specificity could be an artefact of inadequate sampling but in this study 20 fish per species per season were collected which cancels out this possibility. In addition, various studies conducted in the Vaal and Olifants River systems, in which cestode endoparasites have been incorporated, have revealed either 
an absence of cestodes or low infections of them in a range of fish species, namely Clarias gariepinus (Marx 1996; Crafford 2000; Watson 2001), Labeobarbus marequensis (Watson 2001), Oreochromis mossambicus (Watson 2001), Labeo capensis and Labeo umbratus (Groenewald 2000).

When pooling the data according to the sex of the fish, the tapeworms exhibited no preference for male or female fish. Similar numbers of male and female L. kimberleyensis were infected. Even though there were noticeably lower numbers of infected female smallmouth yellowfish when compared to males there was no dependency (statistically) on fish gender.

\section{Size specificity}

In both yellowfish species sampled no correlations were observed between fish size and Asian tapeworm infection (Fig. 5). The statistical $P$ values were closer to 0 than 1 .

\section{CONCLUSION}

In this study, the majority of the tapeworms were identified as $B$. acheilognathi based on the heartshaped scolex and presence of bothria. This was achieved after comparing the specimens collected with the descriptions and sketches in the literature. Bothriocephalus acheilognathi in this study was species (host) specific with a considerably higher infection (in terms of prevalence, abundance and mean intensity) recorded in L. kimberleyensis (largemouth yellowfish). The reason for this has still not been determined. The Asian tapeworm in this study was not fish-gender specific.

Seasonal trends were observed for prevalence, abundance and mean intensity of the tapeworm in $L$. aeneus although statistical analyses indicate that no significant differences existed between seasons. Seasonal trends in smallmouth yellowfish were attributed to breeding and subsequent feeding patterns of the fish.

In L. kimberleyensis, no seasonal trend was recorded for prevalence. The abundance and mean intensities of $B$. acheilognathi, however, varied seasonally with the highest value being recorded in autumn and the lowest value in spring. Statistical analyses indicate that there was a significant difference between the presence of $B$. acheilognathi in these two seasons. The reason for the seasonal trends observed in largemouth yellowfish cannot be explained. Further research on largemouth yellow- fish concentrating on factors such as post-spawning migrations of the host, schooling behaviour, age of host, reproductive behaviour, host feeding behaviour, host hormone levels/state of maturity, immunological response of host, availability of infected intermediate hosts as food, site of infection, negative interaction between parasites (as outlined by Williams \& Jones 1994) should be conducted to provide an explanation as to why there are seasonal variations in $B$. acheilognathis infections in this fish species.

\section{ACKNOWLEDGEMENTS}

We thank the National Research Fund (NRF) and RAU Sasol fund for providing money and Prof. S.N. Mashego for assistance in identifying the tapeworms.

\section{REFERENCES}

BERTASSO, A. 2004. Ecological parameters of selected helminth species in Labeobarbus aeneus and Labeobarbus kimberleyensis in the Vaal Dam, and an evaluation of their influence on indicators of environmental health. M.Sc. dissertation, Rand Afrikaans University.

BOOMKER, J., HUCHZERMEYER, F.W. \& NAUDÉ, T.W. 1980. Bothriocephalosis in the common carp in the Eastern Transvaal. Journal of the South African Veterinary Association, 51: 263-264.

BRANDT, F. DE W., VAN AS, J.G., SCHOONBEE, H.J. \& HAMILTON-ATTWELL, V.L. 1981. The occurrence and treatment of Bothriocephalus in the common carp, Cyprinus carpio in fish ponds with notes on its presence in the largemouth yellowfish Barbus kimberleyensis from the Vaal Dam, Transvaal. Water SA, 7:35-42.

BUSH, A.O., LAFFERTY, K.D., LOTZ, J.M. \& SHOSTAK, A.W. 1997. Parasitology meets ecology on its own terms: Margolis et al. revisited. Journal of Parasitology, 83:575-583.

CRAFFORD, D. 2000. Application of a Fish Health Assessment Index and associated parasite index on Clarias gariepinus (sharptooth catfish) in the Vaal River System, with reference to heavy metals. M.Sc. dissertation, Rand Afrikaans University.

DE LEON, G.P.P., GARCIA-PRIETO, L., LEON-REGAGNON, V. \& CHOUDHURY, A. 2000. Helminth communities of native and introduced fishes in Lake Patzcuaro, Michoacan, Mexico. Journal of Fish Biology, 57:303-325.

DÖRGELOH, W. 1985. Food selection and competition for food among three fish species, Salmo giardneri, Barbus aeneus and Clarias gariepinus. South African Journal of Science, 81: 693.

GROENEWALD, M. 2000. Bioaccumulation of metals and the general health of fish from the Vaal Dam and Vaal River Barrage. M.Sc. dissertation, Rand Afrikaans University.

KHALIL, L. 1991. Techniques for identification and investigative helminthology. St Albans: International Institute of Parasitology.

KHAN, R.A. \& THULIN, J. 1991. Influence of pollution on parasites of aquatic animals. Advances in Parasitology, 30:201- 238. 
KÖRTING, W. 1974. Bothriocephalosis of the carp. Veterinary Medical Review, 2:165-171.

KÖRTING, W. 1975. Larval development of Bothriocephalus sp. (Cestoda: Pseudophyllidea) from carp (Cyprinus carpio L.) in Germany. Journal of Fish Biology, 7:727-733.

MARCOGLIESE, D.J. \& ESCH, G.W. 1989. Experimental and natural infection of planktonic and benthic copepods by the Asian tapeworm, Bothriocephalus acheilognathi. Proceedings of the Helminthology Society of Washington, 56:151155.

MARGOLIS, L., ESCH, G.W., HOLMES, J.C., KURTIS, A.M. \& SCHAD, G.A. 1982. The use of ecological terms in parasitology (Report of an ad hoc committee of the American Society of Parasitologists). Journal of Parasitology, 68:131133.

MARX, H.M. 1996. Evaluation of a Health Assessment Index with reference to metal bioaccumulation in Clarias gariepinus and aspects of the biology of the parasite Lamproglena clariae. M.Sc. thesis, Rand Afrikaans University.

MASHEGO, S.N. 1982. A seasonal investigation of the helminth parasites of Barbus species in water bodies in Lebowa and Venda, South Africa. Ph.D. thesis, University of the North.

MOLNÁR, K. 1977. On the synonyms of Bothriocephalus acheilognathi Yamaguti, 1934. Parasitologia Hungarica, 10: 61-62

MOLNÁR, K. \& MURAI, É. 1973. Morphological studies on Bothriocephalus gowkongensis Yeh, 1955 and B. phoxini Molnár, 1968 (Cestoda, Pseudophyllidea). Parasitologia Hungarica, 6:99-108.

NICKANOR, N., REYNECKE, D.P., AVENANT-OLDEWAGE, A. \& MASHEGO, S.N. 2002. A comparative study of stomach and intestine contents in Barbus aeneus and Barbus kimberleyensis in the Vaal Dam to clarify variance in tapeworm infestation. Journal of South African Veterinary Association, 73(3)142-159.

PANTIN, C.F.A. 1964. Notes on microscopical techniques for zoologists. Cambridge: Cambridge University Press.

PAPERNA, I. 1996. Parasites, infections and diseases of fish in Africa-An update. Rome: FAO (CIFA Technical Paper, no. 31).
POOL, D. 1984. A scanning electron microscope study of the life cycle of Bothriocephalus acheilognathi Yamaguti, 1934. Journal of Fish Biology, 25:361-364.

POOL, D.W. \& CHUBB, J.C. 1985. A critical scanning electron microscope study of the scolex of Bothriocephalus acheilognathi Yamaguti 1934, with a review of the taxonomic history of the genus Bothriocephalus parasitizing cyprinid fish. Systematic Parasitology, 7:199-211.

POOL, D.W. 1987. A note on the synonymy of Bothriocephalus acheilognathi Yamaguti 1934, B. aegyptiacus Ryšavý and Moravec, 1975 and B. kivuensis Baer and Fain, 1958. Parasitology Research, 73:146-150.

POOL, D.W. 1988. An experimental study of the biology of Bothriocephalus acheilognathi Yamaguti 1934 (Cestoda: Pseadophyllidea). Abstract of thesis, University of Liverpool.

POULIN, R. 1998. Evolutionary ecology of parasites: From individuals to communities. London: Chapman \& Hall.

SKELTON, P. 1993. A complete guide to the freshwater fishes of Southern Africa. Halfway House: Southern Book Publishers.

SKELTON, P. 2001. A complete guide to the freshwater fishes of Southern Africa, $2^{\text {nd }}$ ed. Halfway House: Southern Book Publishers.

VAN AS, J.G., SCHOONBEE, H.J. \& BRANDT, F. DE W. 1981. Further records of the occurrence of Bothriocephalus (Cestoda: Pseudophyllidea) in the Transvaal. South African Journal of Science, 77:343.

WATSON, R. 2001. The evaluation of a Fish Health Assessment Index as a biomonitoring tool for heavy metal contamination in the Olifants River catchment area. Ph.D. thesis, Rand Afrikaans University.

WILLIAMS, H. \& JONES, A. 1994. Parasitic worms of fish. London: Taylor \& Francis.

YAMAGUTI, S. 1934. Studies on the helminth fauna of Japan. Part 4: Cestodes of fish. Japanese Journal of Zoology, 6:1112.

YEH, L.S. 1955. On a new tapeworm Bothriocephalus gowkongensis n. sp. (Cestoda: Bothriocephalidae) from freshwater fish in China. Acta Zoologica Sinica, 7:69-74. 